\title{
Engineering Project Development through Sequence of Courses
}

\section{Dr. Nelson Fumo, University of Texas at Tyler}

Nelson Fumo is an Associate Professor at The University of Texas at Tyler. He has a $\mathrm{PhD}$ in Mechanical Engineering from Mississippi State University and a Master's Degree in Mechanical Engineering from the University of Florida. He has been in academia for 30 years and has published more than 60 Journal and Conference papers. His research area is mainly related to buildings energy use with focus on whole building energy modeling, thermal energy systems design and optimization, and HVAC and solar energy applications. However, his passion for student success has recently motivated him to work on educational projects leading to the publication of two journal papers and one conference paper that support engineering education. 


\title{
Engineering Project Development through Sequence of Courses
}

\begin{abstract}
For years, several groups have researched the effectiveness of project-based learning (PBL) in classrooms. Most have shown positive results, suggesting that students' knowledge of the subject, as well as skills like teamwork and problem solving, improve more with this teaching style than with traditional lecturing. While some of the studies have studied the effect of PBL in the engineering curriculum, the projects were completed in single classes.
\end{abstract}

In this study, a PBL approach is implemented by developing projects in a series of required courses in a Mechanical Engineering curriculum. The projects assigned in each course are related and planned to build up the knowledge and skills needed to develop a successful senior design project or capstone project. In implementing the approach, the instructor identifies the topic or problem to be proposed as a senior design project. In the first of the sequential courses, an experimental measurements laboratory course, a project is assigned regarding a sensor that could be used in the senior design project. In the second of the sequential courses, a thermal-fluids laboratory course, a project is assigned in which the students use the sensor from the previous project to develop a project that requires the application and demonstration of the use of the sensor to achieve a specific mechanical requirement. In the following sequential courses, the two senior design courses, students use the knowledge and experience gained to develop the final project which topic or problem was identified by the instructor before the approach was initially implemented in the first of the sequential courses.

To assess the impact of the approach, surveys were given to the students in each course to determine whether students felt that the projects helped them with the learning process as well as to have some direct impact in their future professional careers. Two groups/cohorts have been through this approach (of a sequence of courses) so far. The results suggest that the approach may have better results than working in a senior design project without the previous experience/knowledge gained through the approach presented in this paper. Results from these two groups/cohorts also suggest that the interest the project generates in the students is a key factor for the overall goal of the approach.

\section{Introduction}

In 2008, using data collected by the National Survey of Student Engagement, George Kuh [1] examined several educational practices thought to be high-impact in terms of the benefits they offer students. One of the practices highlighted was the capstone or senior project, which utilizes many of the subjects learned throughout a student's college career and applies them to a realistic situation or problem [1]. This method of teaching is known as Project-Based Learning or PBL.

Research on this teaching method, as well as experiences from educators, has shown that PBL can dramatically benefit students in a range of areas. In 2007, the NSSE found that "students who do a capstone seminar that requires a final product or performance gain more in desired areas compared with their peers whose capstones do not require a final product or performance" [1]. Rachelle Poth, a high school teacher in Pennsylvania, shared her personal experience with 
how PBL benefits students. For example, Poth brings up the point that since many students are not good test-takers, PBL can be utilized to provide a more authentic assessment of students' knowledge, on top of building additional skills [2].

In his 2000 paper "A Review of Research on Project-Based Learning," Thomas used numerous studies of PBL to display the benefits it provides to students in multiple areas, such as student achievement, problem-solving capabilities, and understanding of subject matter [3]. Benefits in student achievement were shown by Han, R. Capraro, and M. Capraro, who examined the effects of STEM PBL on mathematics test scores for students of different levels of academic achievement. Their study found that while all groups showed improvement, the scores of low performing students benefitted greatly from PBL [4]. Further examples include multiple studies on the use of PBL to enhance the engineering curriculum. These studies all concluded that giving students projects, especially those centered around real-world applications, can improve skills such as teamwork and problem-solving in engineering students, along with increased motivation and interest [5], [6], [7].

The purpose of this paper is to show how PBL can be used in the engineering curriculum throughout a series of courses to further enhance the benefits shown in research, while also helping them to build skills that are necessary for their future careers.

\section{Rationale/Need}

For better understanding and internalization of theoretical knowledge learned in fundamental courses, the knowledge needs to be applied to practical and relevant cases. Also, it is important that students apply concepts in steps, allowing the development of new knowledge and skills from previous knowledge in a summative way. With these ideas in mind, the approach presented in this paper has the following characteristics that facilitate the achievement of benefits regarding increasing engagement, active learning, meeting learning outcomes, student success, and professional success:

- Projects assigned are related to a real apparatus/device used in an engineering application

- Projects require experimental validation and calibration

- Projects expose students to multiple setbacks related to the development of a product, which will be encounter as a professional.

- Students need to research the topic associated with the project to propose their own design, which promotes active learning

- Students work on a Technical Report instead of a lab report to satisfy the "Write clear and well-documented laboratory reports" learning outcome stated in the syllabus of two lab courses. This helps students to write a report with an engineering mindset instead of a student mindset.

\section{The Approach}

The Engineering Project Development through Sequence of Courses approach divides the development of a Senior Design Project or Capstone Project into small projects to be developed in previous laboratory courses of the curriculum. The approach starts with the conception of a product for a specific application by the instructor, which facilitates the division of the 
intellectual effort among the sequential courses. For the Mechanical Engineering curriculum of the institution, the approach is applied as illustrated in Figure 1 and Table 1. In the Fall semester, in the Lab Course 1, students work on selecting and testing a sensor that can be used in a measurement system to be developed in the next sequential course. In the Spring semester, in the Lab Course 2, students work on building and testing a measurement system that could be incorporated into the conceived product. For their Capstone Project, developed during two semesters, students design and build a prototype of the product for the defined specific application.

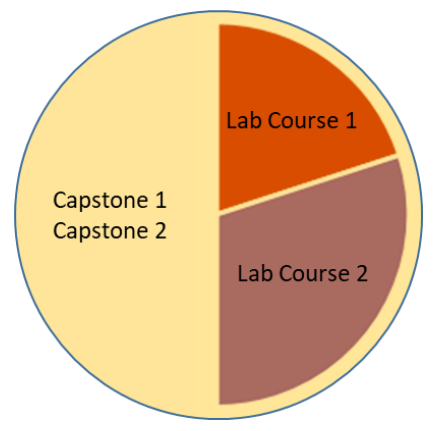

Table 1. Structure of application of the approach.

\begin{tabular}{|l|l|l|}
\hline \multicolumn{1}{|c|}{ Semester } & \multicolumn{1}{c|}{ Course } & \multicolumn{1}{c|}{ Project Phase } \\
\hline Fall & Lab Course 1 & Sensor(s) \\
\hline Spring & Lab Course 2 & Measurement system \\
\hline Fall/Spring & Capstone 1 and 2 & Prototype \\
\hline
\end{tabular}

Fig. 1 Distribution of Intellectual Effort.

It is important to point out that the Lab Course 1 is a prerequisite of the Lab Course 2, and the Lab Course 2 is a prerequisite of the Capstone 1 course. Therefore, the sequence of courses imposes a constrain to the approach for those students that miss one of the courses in the sequence for a specific project. Although the instructor is aware of this situation, the statistics based on seven years show that it is very improbable that a student does not take all the courses as planned. This is mainly because the lab courses are not courses with passing issues and because they are offered once a year and students know that if they do not pass any of the two lab courses it will put them one year back on the expected graduation date.

\section{Executed Projects}

The projects developed through this approach formally started in Fall 2017. However, the idea came from the capstone project developed during the 2016-2017 academic year, which is described below as the First Initiative. So, formally the approach has been implemented for three cohorts/projects, one for the period 2016-2018 (Fall 2016-Spring 2018) and another for the period 2017-2019 (Fall 2017-Spring 2019).

\section{First Initiative}

As part of the research interest and initiatives of the instructor, the instructor wanted to work on a residential zoning system. Therefore, in Spring 2016, in the Lab Course 1, students were asked to experimentally validate the response of a damper for variable air volume in HVAC systems. A picture of one of the projects successfully developed by students is shown in Figure 2. 


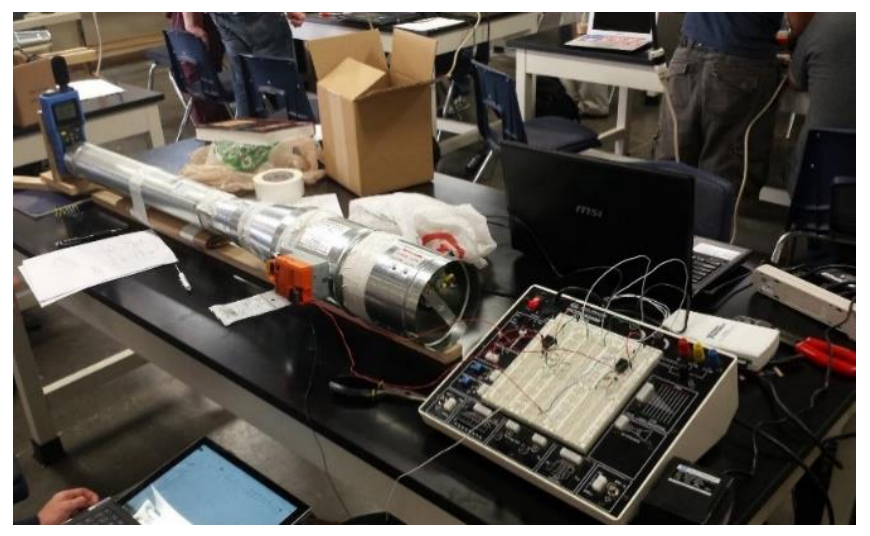

For a group of five students, this project was the first stage of a larger project developed in the Senior Design course for the academic year 2016-2017. The project was the Auto Self-Balanced Zoning System which was successfully developed and ranked as the top project during the Senior Design Expo in Spring 2017.

Fig. 2 Picture of Apparatus Developed for the Response of Dampers Project.

\section{Project 2016-2018}

\section{Background/Justification}

In air distribution systems used in the HVAC industry, the air velocity (or airflow) is especially needed as a control variable to keep a system balanced while assuring thermal comfort and energy efficiency. For the HVAC industry, it seems that the averaging Pitot tube is the preferable choice for airflow measurement because of its cost and reasonable accuracy. However, this type of measuring system is not recommended for low velocities. For this capstone project, the main objective was to design, build, test, and calibrate a Duct Mounted Airflow Measurement Device (DMAMS) that could be installed in a residential application along with current systems in place.

\section{MENG 3210 (Fall 2016) - Measuring Tension on a String Using a Strain Gage}

The project was about the use of the concept of drag force on a string as a sensing element to measure average air velocity in a duct. Since the velocity profile in ducts is not uniform, the air on a string across the duct could give an average velocity. The goal of the project was to measure the tension on a string using a strain gage. A picture of one of the projects developed by students is shown in Figure 3.

\section{MENG 3211 (Spring 2017) - Duct Mounted Airflow Measurement System}

Since students have gained some experience in using a sensor for averaging velocity, the main goal of the project was the experimental validation of the design and construction of a duct mounted airflow measurement system for residential HVAC ducts. A picture of one of the projects developed by students is shown in Figure 4.

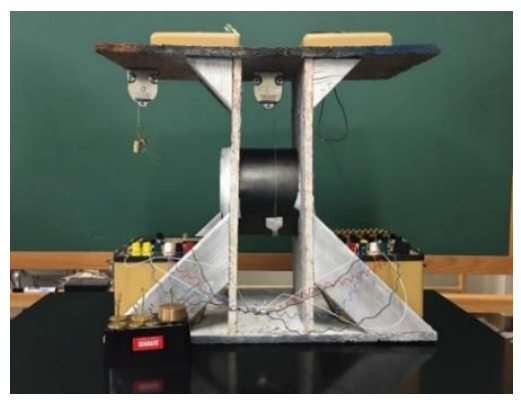

Fig. 3 Apparatus Developed for the Measuring Tension on a String.

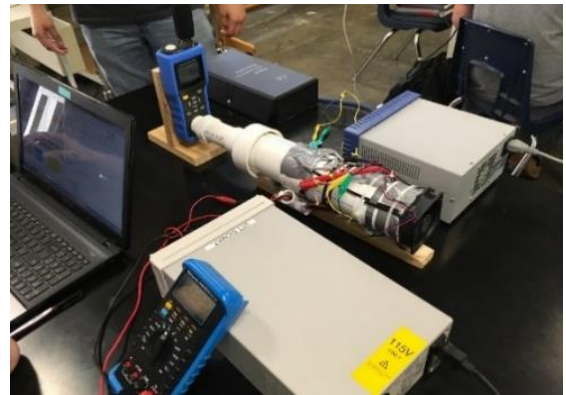

Fig. 4 Apparatus Developed for the Duct Mounted Airflow Measurement System. 


\section{Objective}

Design, built, test and calibrate a Duct Mounted Airflow Measurement System (DMAMS).

\section{System Requirements}

1) The device must be designed for a circular duct with a diameter of at least 8 inches. So, industry standards must be followed for a typical installation/coupling.

2) The device must have its own transducer or use a standard commercially available transducer to express velocity as a voltage or current.

3) The device must be tested using a rig that satisfies industry (HVAC industry) standards (ASHRAE standards for example).

4) The device must average the air velocity of the air in the duct with at least the number of points specified by ASHRAE standards.

For this project, two teams of four students competed. To avoid replication, one requirement was that the physical principle of response of the device should be different. As a result, the project shown in Figure 5-a was based on heat transfer and the prototype shown in Figure 5-b was based on differential pressure.

(a)
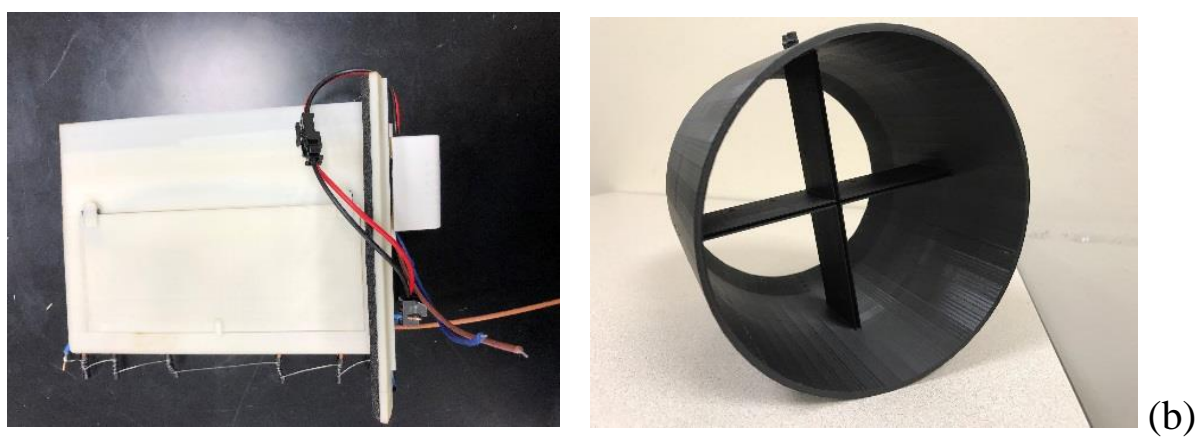

Fig. 5 Picture of Prototypes for the Duct Mounted Airflow Measurement System Project, (a) prototype based on heat transfer principles and (b) based on differential pressure.

\section{Project 2017-2019}

\section{Background/Justification}

In residential HVAC systems, air is distributed from the air handler unit to the rooms through ducts. The end of a duct branch supplying air to a room is a supply register such as the ones shown in Figure 6. Registers are used to direct the flow in specific directions, as well as to help balance the system by having capabilities to restrict the flow.

Flow hoods, like the ones shown in Figure 7, have been used for many years by the HVAC industry as a method of measuring the air flows at registers for balancing, but they are designed for commercial applications [8]. They are kind of bulky because they have been designed to cover a large range of registers' size, mainly for commercial applications, and their accuracy for residential applications has been questioned [9]. 

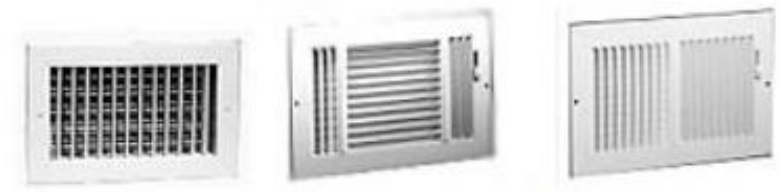

Fig. 6 Example of Residential Registers.
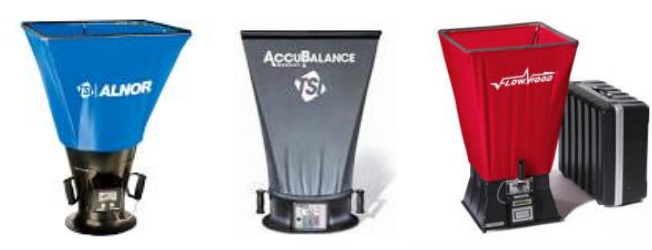

Fig. 7 Example of Flow Hoods used in Commercial Applications.

MENG 3210 (Fall 2017) - Sensor for Measuring Airflow in Residential Supply Registers The project was about the use of any technology that could be applied in airflow capture hoods capable of measuring low airflow rates since that is the main source of errors from commercially available products. The main goal of the project was the experimental validation of a sensor that could be used in a measurement system for measuring airflow in residential supply registers. Figure 8 shows a picture of one of the apparatus developed by students.

\section{MENG 3211 (Spring 2018) - Airflow Capture Hood for Residential Supply Registers}

Since students had gained some experience in using a sensor for measuring air flow rate, the main goal of the project was to design, build, and test an airflow capture hood for residential supply registers. Figure 9 shows a picture of one of the apparatus developed by students.

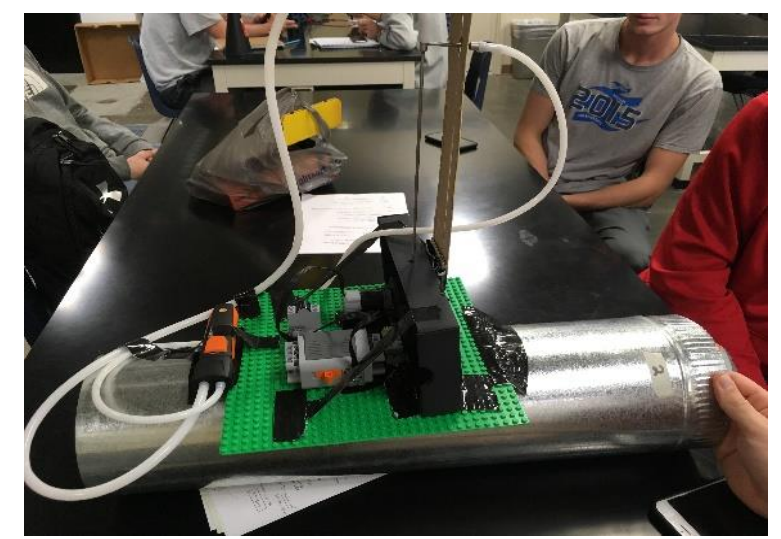

Fig. 8 Picture of an Apparatus Developed for the Sensor for Measuring Airflow in Residential Supply Registers Project.

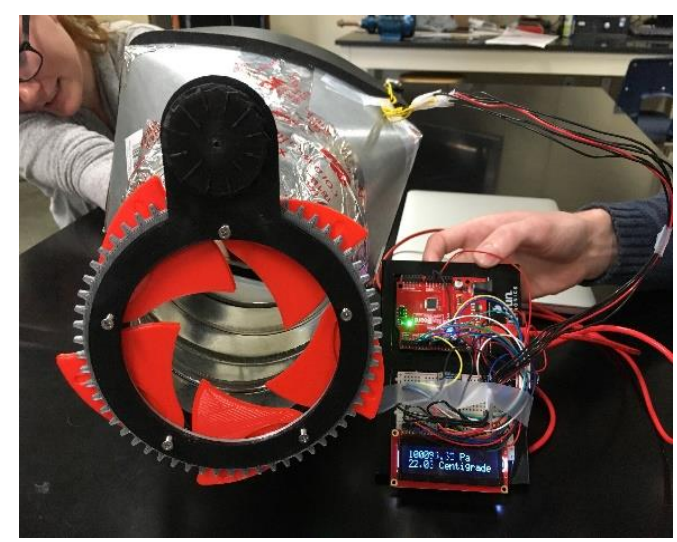

Fig. 9 Picture of an Apparatus Developed for the Airflow Capture Hood for Residential Supply Registers Project.

MENG $4115 / 4315$ (Fall 2018/Spring 2019) - Airflow Capture Hood for Residential Supply The Proposal for the Senior Design project was as follows:

Objective

Design, built, test and validate an Airflow Capture Hood for Residential Registers.

\section{System Requirements}

1) The final product must be able to measure airflow rates from residential registers.

2) The final product must be a standalone product such as commercially available products.

3) The final product must be able to measure airflow of 20 CFM with an accuracy equal or better than $5 \%$ and equal or better than $3 \%$ for airflow rates greater than $100 \mathrm{CFM}$. 
4) The final product must be simple to manufacture at a commercial scale and not weigh more than commercially available products.

\section{Methodology Evaluation}

\section{Project Fall 2016-Spring 2018 Assessment}

To assess the impact of the approach on the students learning, two surveys were applied. One at the beginning, shown in Table 2, and another at the end, shown in Table 3, of the Spring 2017 semester in the Lab Course 1. The questions and results of the surveys are:

Table 2. Results from Survey 1, project 2016-2018.

\begin{tabular}{|c|c|c|c|c|c|c|}
\hline Question & Extremely & Very & Somewhat & Not so & Not at all & Not sure \\
\hline $\begin{array}{l}\text { How effective was the project 'Measuring Tension on a String Using a Strain Gage' to learn } \\
\text { and apply concepts regarding the use of strain gages? }\end{array}$ & 9 & 13 & 7 & 1 & 0 & $\mathrm{~N} / \mathrm{A}$ \\
\hline $\begin{array}{l}\text { How sufficient was the project 'Measuring Tension on a String Using a Strain Gage' as a hands- } \\
\text { on project on using strain gages? }\end{array}$ & 6 & 13 & 11 & 0 & 0 & N/A \\
\hline $\begin{array}{l}\text { How important was the project 'Measuring Tension on a String Using a Strain Gage' developed } \\
\text { in MENG } 3210 \text { to give you an experience that can help you in your future professional career? }\end{array}$ & 3 & 12 & 11 & 3 & 0 & 1 \\
\hline $\begin{array}{l}\text { How important was the project 'Measuring Tension on a String Using a Strain Gage' as an } \\
\text { experience to help you to develop the project 'Duct Mounted Airflow Measurement System' } \\
\text { assigned in MENG } 3211 \text { - Mechanical Engineering Lab II in Spring } 2017 \text { semester? }\end{array}$ & 6 & 8 & 12 & 3 & 1 & $\mathrm{~N} / \mathrm{A}$ \\
\hline
\end{tabular}

Table 3. Results from Survey 2, project 2016-2018.

\begin{tabular}{|c|c|c|c|c|c|c|}
\hline Question & Extremely & Very & Somewhat & Not so & Not at all & Not sure \\
\hline $\begin{array}{l}\text { How effective was the project 'Duct Mounted Airflow Measurement System' to offer an } \\
\text { opportunity to understand the importance of an engineering design before a model or } \\
\text { prototype is built? }\end{array}$ & 21 & 15 & 3 & 0 & 0 & N/A \\
\hline $\begin{array}{l}\text { How effective was the project 'Duct Mounted Airflow Measurement System' to offer an } \\
\text { opportunity to understand the importance of calibration? }\end{array}$ & 21 & 15 & 3 & 0 & 0 & N/A \\
\hline $\begin{array}{l}\text { How effective was the project 'Duct Mounted Airflow Measurement System' to offer a hands- } \\
\text { on learning experience regarding the development of an engineering project? }\end{array}$ & 22 & 16 & 1 & 0 & 0 & N/A \\
\hline $\begin{array}{l}\text { How important was the project 'Duct Mounted Airflow Measurement System' developed in } \\
\text { MENG } 3211 \text { to give you an experience that can help you in your future professional career? }\end{array}$ & 15 & 11 & 12 & 1 & 0 & 0 \\
\hline $\begin{array}{l}\text { Would you be interested in participating in the design and construction of a marketable Duct } \\
\text { Mounted Airflow Measurement Station for HVAC applications as a Senior Design project? }\end{array}$ & 7 & 8 & 18 & 4 & 0 & 2 \\
\hline
\end{tabular}

Results from the two surveys suggest that the intended purpose of the approach was achieved through the assigned project, as well as the methodology. The Heating, Ventilation and Air Conditioning (HVAC) related project was a great experience for the eight students developing the project as their senior design project. Five of them were doing internships at a local manufacturer of residential HVAC systems by the time they were working on the project and one of them was also awarded a scholarship $(\$ 3,000)$ from the American Society of Heating, Refrigerating, and Air Conditioning Engineers (ASHRAE). On the other hand, this senior design project received funds from an ASHRAE Grant in the amount of \$1,600.

The students were so involved in the project development that they made a presentation for the the local ASHRAE Chapter and they were asked to provide their honest feedback about the project after the Senior Design Expo 2018. Their feedback was motivating and shows what it was expected from this approach and some recommendations were also well received. The emails received from students, which includes their names, are available on demand but excerpts from their emails are given below to support the achievement of the goal of the approach: 
Student \#1 wrote: "Three projects in-sequence helps develop interest and knowledge in a particular subject area. Here, the subject is HVAC - and I've spent a lot of time now learning about the topic. I have gained an understanding for the residential and commercial HVAC markets, their components, how innovation in the field is focused on improved efficiency, challenges in controlling the system and measuring quantities, and others just to name a few. Now, I feel confident that I have sufficient background knowledge to join the industry and be successful."

Student \#2 wrote: "By combining multiple semester projects under the scope of one outcome, a truly unique and complete senior design project can be accomplished. Under normal circumstances, one year is simply too small of a period to conduct adequate design and testing of an innovative and exciting project; but with an extra semester or two to begin understanding the basic mechanics and underlying phenomena of a certain subject, great engineering can be achieved."

Student \#3 wrote: "Starting on the Senior Design Project, I was optimistic due to background received in the previous semester projects. Students have an advantage when developing a project that they have already put much thought and effort into. It also contributes to the understanding of the purpose of the project. For me, this is an important factor. If I understand the bigger picture and the possibilities of the end result, I am more willing to invest the time."

Student \#4wrote: "My experience with having the final project as a continuation of the previous two semester projects has been very positive. I felt that the quality of the project was improved by using this progressive technique. Because the previous semesters fed into the final project, it allowed the team to continue to build on lessons learned in the previous semesters. I feel like this is an approach that allows the student a deeper understanding of a subject matter and helps to develop professional skills needed in the industry."

Student \#5 wrote: "I feel as though the entire experience of developing an airflow measurement device was enhanced by beginning the project in the Junior year with Mechanical Engineering Lab 1. Even though we did not use any of our previous concepts for our final design unlike the other team, the previous experience helped to rule out ideas that certainly wouldn't work. Even though it started to get old trying to develop truly new concepts to solve an existing problem a new way, it was excellent engineering experience to stick with each design until they were deemed unusable, and then moving onto the next best idea."

Student \#6 wrote: "Going through all the projects back to back to back definitely helped with the stages of development. I was able to learn the basics of all the components that could be used in an airflow sensor in the MENG $3210 \mathrm{Lab}$. Then in MENG $3211 \mathrm{Lab}$, we were able to have some more freedom in designing a measurement system. During this lab, I learned more of what problems are encountered and what might be needed to fix them. Also, being able to see the wide range of projects created gave me more ideas as to what could be designed in the future. Which led into the senior design project allowing us to have a wide background on the concept. This process helped in not technically having to start from scratch and applying previous projects in our final design process." 
Student \#7 wrote: "The approach developed to carry out this project in three phases is very appealing and rather interesting. However, I feel there are some caveats as the last two phases last well over a year period. I think as a student, being on the same project does have promises but with the wide variety of courses and electives, being limited to a mirror project from the laboratory section has potential to place some weariness over that course of junior/senior years. The project was enjoyable but there were definitely dips in enthusiasm just as development was extremely difficult to derive a new method of measurement."

\section{Project Fall 2017-Spring 2019 Assessment}

For this project, only one survey was applied at the end of the two laboratory courses in Spring 2018. Questions are the same as for the second survey of the previous project, but an additional question was added to summarize the goal of the first survey of the previous project. The results of the survey are shown in Table 4. The seven students that selected 'Not Sure' in Question 6 were students that did not take MENG 3210 in Fall 2017 but in Fall 2016. Therefore, they did not go through the experience of the previous project developed in Fall 2018.

Table 4. Results from the survey for project 2017-2019.

\begin{tabular}{|c|c|c|c|c|c|c|c|c|c|c|c|c|}
\hline Question & \multicolumn{2}{|c|}{ Extremely } & \multicolumn{2}{|c|}{ Very } & \multicolumn{2}{|c|}{ Somewhat } & \multicolumn{2}{|c|}{ Not so } & \multicolumn{2}{|c|}{ Not at all } & \multicolumn{2}{|c|}{ Not sure } \\
\hline $\begin{array}{l}\text { How effective was the project "Airflow Capture Hood for Residential Supply Registers" to } \\
\text { offer an opportunity to understand the importance of an engineering design before a model } \\
\text { or prototype is built? }\end{array}$ & 12 & $29 \%$ & 15 & $36 \%$ & 10 & $24 \%$ & 4 & $10 \%$ & 1 & $2 \%$ & & /A \\
\hline $\begin{array}{l}\text { How effective was the project "Airflow Capture Hood for Residential Supply Registers" to } \\
\text { offer an opportunity to understand the importance of calibration? }\end{array}$ & 14 & $33 \%$ & 21 & $50 \%$ & 5 & $12 \%$ & 1 & $2 \%$ & 1 & $2 \%$ & & /A \\
\hline $\begin{array}{l}\text { How effective was the project "Airflow Capture Hood for Residential Supply Registers" to } \\
\text { offer a hands-on learning experience regarding the development of an engineering project? }\end{array}$ & 14 & $33 \%$ & 20 & $48 \%$ & 6 & $14 \%$ & 1 & $2 \%$ & 1 & $2 \%$ & & /A \\
\hline $\begin{array}{l}\text { How important was the project "Airflow Capture Hood for Residential Supply Registers" } \\
\text { developed in MENG } 3211 \text { to give you an experience that can help you in your future } \\
\text { professional career? }\end{array}$ & 8 & $19 \%$ & 10 & $24 \%$ & 15 & $36 \%$ & 4 & $10 \%$ & 3 & $7 \%$ & 2 & $5 \%$ \\
\hline $\begin{array}{l}\text { Would you be interested in participating in the design and construction of a marketable } \\
\text { Airflow Capture Hood for Residential Supply Registers as a Senior Design project? }\end{array}$ & 3 & $7 \%$ & 4 & $10 \%$ & 14 & $33 \%$ & 6 & $14 \%$ & 14 & $33 \%$ & 1 & $2 \%$ \\
\hline $\begin{array}{l}\text { How important was the project "Sensor for Measuring Airflow in Residential Supply Registers" } \\
\text { developed in MENG } 3210 \text { in Fall } 2017 \text { as a previous experience to help you to develop the } \\
\text { project "Airflow Capture Hood for Residential Supply Registers" assigned in MENG } 3211 \text { in } \\
\text { Spring } 2018 \text { semester? }\end{array}$ & 3 & $7 \%$ & 14 & $33 \%$ & 13 & $31 \%$ & 4 & $10 \%$ & 1 & $2 \%$ & 7 & $17 \%$ \\
\hline
\end{tabular}

During the academic year 2018-2019, a group of four Mechanical Engineering students is working on the Senior Design project and as with the previous cohort, their honest feedback about the approach will be asked as further assessment of the approach.

Results from the survey suggest that the intended purpose of the approach was achieved but at a lower level than the previous project. The instructor own assessment is that the project was not as appealing as the previous semester project, which may be supported by the answers to Question 5. However, the four ME students working on their Senior Design project have shown more enthusiasm and dedication to what it was expected. The results from the Senior Design Expo 2019 and their feedback will allow the instructor to drive the final conclusions from this project in order to compare results with the previous project.

\section{Continuing the Work}

The approach has been applied for the cohort Fall 2018-Spring 2020. The project selected for this period is also related to the HVAC industry. For the capstone project, the goal is the 
construction of a laboratory apparatus for research related to demand control ventilation (DCV) [10], [11]."

As part of an approach to develop the capstone project, in the Lab Course 1 the project was related to $\mathrm{CO}_{2}$ sensors used in DCV. In the Lab Course 2, the project was related to the design, analysis, and documentation of an experimental procedure to test the $\mathrm{CO}_{2}$ sensor used in the previous lab course for potential application in DCV systems.

\section{Conclusions}

Results from the surveys as well as participation and feedback from students in the related capstone projects suggest that the intended purpose of the approach was achieved. Students were exposed to a real-world experience while satisfying the Mechanical Engineering curriculum course requirements.

\section{References}

[1] G. D. Kuh, "High-Impact Educational Practices: What They Are, Who Has Access to Them, and Why They Matter," AAC\&U, 2008.

[2] R. Poth, "EasyBib," 9 November 2016. [Online]. Available: http://www.easybib.com/guides/project-based-learning-benefits-students/. [Accessed 22 September 2018].

[3] J. Thomas, "A REVIEW OF RESEARCH ON PROJECT-BASED LEARNING," The Autodesk Foundation, San Rafael, 2000.

[4] S. Han, R. Capraro and M. M. Capraro, "HOW SCIENCE, TECHNOLOGY, ENGINEERING, AND MATHEMATICS (STEM) PROJECT-BASED LEARNING (PBL) AFFECTS HIGH, MIDDLE, AND LOW ACHIEVERS DIFFERENTLY: THE IMPACT OF STUDENT FACTORS ON ACHIEVEMENT," International Journal of Science and Mathematics Education, vol. 13, no. 5, pp. 1089-1113, 2015.

[5] H. Hadim and S. Esche, "Enhancing the engineering curriculum through project-based learning," in 32nd Annual Frontiers in Education, Boston, 2002.

[6] I. D. L. Rios, J. M. Díaz-Puente, A. C. Montero and J. L. Y. Blanco, "Project-based learning in engineering higher education: Two decades of teaching competences in real environments," Procedia - Social and Behavioral Sciences, vol. 2, no. 2, pp. 1368-1378, 2010.

[7] J. E. Mills and D. F. Treagust, "ENGINEERING EDUCATION - IS PROBLEM-BASED OR PROJECT-BASED LEARNING THE ANSWER?," Australasian Journal Of Engineering Education, 2003.

[8] I. Walker, C. Wray, D. Dickerhoff and M. Sherman, "Evaluation of flow hood measurements for residential register flows," Lawrence Berkeley National Laboratory, Berkeley, CA, 2001.

[9] I. Walker and C. Wray, "Evaluation of flow capture techniques for measuring HVAC grille airflows," Lawrence Berkeley National Laboratory, Berkeley, CA, 2002. 
[10] Building Technologies Program, Department of Energy, "Demand Control Ventilation," 2012. [Online]. Available:

https://www.energycodes.gov/sites/default/files/documents/cn_demand_control_ventilation.pdf. [Accessed September 2018].

[11] TRANE, "CO2-Based Demand-Controlled Ventilation with ASHRAE Standard 62.1-2004," TRANE Engineers Newsletter, Vol. 34-5, p. 7, November 2005.

\section{Acknowledgment}

The author wants to thank all the students that directly or indirectly participated in the approach, but especially to those that were part of the cohorts working on the capstone projects developed through the approach presented in this paper. 